\title{
Differentiating between calcites formed by different mechanisms using infrared spectrometry: archaeological applications
}

\section{Lior Regev ${ }^{\text {a, }}$, Kristin M. Poduska ${ }^{\text {b }}$, Lia Addadi ${ }^{\text {a }}$, Steve Weiner ${ }^{\text {a }}$ and Elisabetta Boaretto $^{c, d}$}

${ }^{\text {a }}$ Department of Structural Biology and the Kimmel Center for Archaeological Science, Weizmann Institute of Science, Rehovot 76100, Israel.

${ }^{\mathrm{b}}$ Department of Physics and Physical Oceanography, Memorial University of Newfoundland, St. John's, NL A1B 3X7, Canada.

${ }^{\mathrm{c}}$ Radiocarbon and Cosmogenic Isotopes Laboratory, Kimmel Center for Archaeological Science, Weizmann Institute of Science, 76100 Rehovot, Israel.

${ }^{\mathrm{d}}$ Department of Land of Israel Studies and Archaeology, Bar-Ilan University, Ramat-Gan 52900, Israel.

* Corresponding author at: Kimmel Center for Archaeological Science, Weizmann Institute of Science, 76100 Rehovot, Israel. Tel.: 9728934 6275; fax: 97289346062. E-mail address: lior.regev@weizmann.ac.il (L. Regev).

Keywords: Calcium carbonate, infrared spectroscopy, pyrotechnology, diagenesis, ash, plaster

\begin{abstract}
Infrared spectrometry is a well established method for the identification of minerals. Due to its simplicity and the short time required to obtain a result, it can be practiced on-site during excavation using portable infrared spectrometers. However, the identification of a mineral may not be sufficient. For example, a lime plaster floor and a crushed chalk surface have similar appearance and are composed of the same mineral calcite. Here we exploit differences in the infrared spectra of geogenic, biogenic and pyrogenic calcites for the identification of each calcite type. The infrared calcite spectrum has three characteristic peaks in the region of $400-4000 \mathrm{~cm}^{-1}$, designated $v_{2}, v_{3}$, and $v_{4}$.
\end{abstract}


When a calcite sample is ground, as part of the measurement preparation procedure, some grinding dependent changes will be revealed in the infrared spectrum. With additional grinding, the $v_{3}$ peak narrows and the heights of the $v_{2}$ and $v_{4}$ peaks decrease, when both are normalized to the $v_{3}$ height. By plotting the normalized heights of the $v_{2}$ versus the $v_{4}$ of several grindings of the same sample, a characteristic trend line is formed for each calcite type. The trend lines of geogenic calcites have the mildest slopes and highest $v_{4}$ values when compared to pyrogenic calcites, which can be further divided to ash and plaster/mortar samples. This method can assist in the differentiation of the various calcites, including insights on homogeneity and preservation state of the calcitic materials in question.

\section{Introduction}

Calcite is a common mineral in geological and archaeological contexts. Calcite is the main component of limestone, chalk, marble, travertine, and is often a major component of wind-borne sediment (loess) and cemented sediments. Calcite is also a common component of invertebrate shells and other skeletal elements, and is produced anthropogenically in the form of wood ash, as well as plaster and mortar. All of these forms of calcite can be found in archaeological sites, sometimes in considerable quantities. Although the identification of the various calcite types present in archaeological sites is sometimes straightforward, difficulties may arise. For instance, a white crushed chalk surface can be mistakenly identified as a lime plaster floor. Fine grained ash calcite is often difficult to identify, as it can undergo diagenetic changes, and/or be intimately mixed with the local sediment that may contain geogenic calcite. The identification of the different forms of calcite in an archaeological site can provide information on the activities performed in different areas of the site, such as various pyrotechnological activities, and can shed light on aspects of site formation processes. Here we demonstrate how Fourier transform infrared spectrometry (FTIR) can be used to differentiate among calcites formed by different mechanisms. We illustrate the use of the approach by analyzing the various calcite components of an ancient plaster. 
Geogenic, biogenic and pyrogenic calcites are formed by different mechanisms, and this in turn can influence characteristics such as crystallinity, coherence length, domain size, and crystal habit. Large geogenic calcite crystals, with well defined crystal habits, are presumed to form slowly from saturated solutions. In contrast, many biogenic calcites are thought to form via an amorphous calcium carbonate precursor phase that crystallizes in vivo (Addadi et al., 2003; Beniash et al., 1997; Gago-Duport et al., 2008; Politi et al., 2008). Chalk and limestone typically originate as biogenic calcite, but they have often undergone dissolution and reprecipitation processes to different extents (Pettijohn, 1957). The two main forms of pyrogenic calcites found in archaeological sites are wood ash and lime plaster/mortar, each with a different formation pathway. Lime plaster or mortar is formed when limestone or chalk is heated near $750^{\circ} \mathrm{C}$, at which point the calcium carbonate decomposes to calcium oxide $(\mathrm{CaO})$ and carbon dioxide (Boynton, 1980 , pp. 159, 162). Water is then added to form hydrated lime $\left(\mathrm{Ca}(\mathrm{OH})_{2}\right)$. The slaked lime is often mixed with other additives to increase volume and strength. These additives are frequently in the form of geogenic calcite (Borrelli, 1999). When the paste is set as surfaces or a binding material, it dehydrates and absorbs carbon dioxide from the atmosphere to reform as calcite. Wood ash is usually formed from calcium oxalate crystals $\left(\mathrm{CaC}_{2} \mathrm{O}_{4}\right)$ found in the wood. When heated to around $500^{\circ} \mathrm{C}$, the calcium oxalate decomposes to calcite $\left(\mathrm{CaCO}_{3}\right)$ by the release of carbon monoxide (CO) (Dollimore, 1987; Huaqing, 1989). Wood ash calcite may also be exposed to temperatures above $750^{\circ} \mathrm{C}$ in kilns and ovens used for various pyrotechnological activities. This ash will decompose to $\mathrm{CaO}$ and reform as calcite in the same way as lime plaster forms (Canti, 2003; Dollimore, 1987; Huaqing, 1989).

Infrared spectroscopy is a well-established method for identifying different mineral and organic components in archaeological samples. These material-specific IR "fingerprints" are possible because the peaks in an infrared spectrum are the result of the absorption of photons at specific energies corresponding to vibrations or rotations of molecules or of specific chemical bonds within them. Any change in the character of these bonds will change the characteristic energy of its vibration and can result in a change in the peak shape, width, height, and/or position. Particularly relevant to this study is that the vibrational and rotational infrared spectra are sensitive to the molecular 
environment, both crystalline and amorphous. In addition, it is well documented that differences in particle sizes and morphologies can also affect the sizes and shapes of IR absorption peaks (Duyckaerts, 1959; Lane, 1999; Ruppin and Englman, 1970). An infrared spectrum is therefore affected by order within a material, both at the local atomic level and at longer length scales.

Calcite has three characteristic IR absorption peaks in the range between 4004000 wavenumbers (measured in $\mathrm{cm}^{-1}$ units, which is the reciprocal of wavelength): $v_{3}$ at $1420 \mathrm{~cm}^{-1}, v_{2}$ at $874 \mathrm{~cm}^{-1}$, and $v_{4}$ at $713 \mathrm{~cm}^{-1}$. All of these absorptions are influenced by the different ways in which the $\mathrm{C}-\mathrm{O}$ bonds of the carbonate unit interact with the infrared radiation. It has been shown experimentally (Addadi et al., 2003; Aizenberg et al., 1997; Beniash et al., 1997; Politi et al., 2004) and theoretically (Gueta et al., 2007) in biogenic calcite from the sea urchin Paracentrotus lividus, that the ratio of the $v_{2} / v_{4}$ peak heights decreases as the initially deposited amorphous calcium carbonate crystallizes into calcite. Chu et al. (2008) used the $v_{2} / v_{4}$ peak heights ratio to distinguish between geogenic and pyrogenic calcites in archaeological contexts. The same study also showed that the calcite $v_{3}$ absorption peak narrows with increased grinding of the sample as the $v_{2} / v_{4}$ ratio increases.

Here we present a new approach for using the infrared spectra of calcite for differentiating among calcites formed by different processes. We show that the relative IR peak heights change with grinding in a consistent way in a single material, and that calcites of different origins have different relative peak heights. This allows us to more reliably differentiate between different geogenic, biogenic, and pyrogenic calcites, and in addition does not require that all samples be ground to the same extent. This approach can be used for rapid sample analysis in the field.

\section{Materials and Methods}

2.1. Materials: Geogenic samples were collected in Israel. Limestones were collected from coastal Tel Dor (20 km south of Haifa, see Sharon et al., 2009, designated as 'Limestone A' in the paper) and from Tel Tsafit (Tell es-Safi/Gath, $20 \mathrm{~km}$ south-east of Ashdod, see Maeir, in press, 'Limestone B'). Chalk samples were collected from Ramat- 
Rachel archaeological site close to Jerusalem (Lipschits et al., 2009, 'Chalk A'), and from Tel Tsafit ('Chalk B'). The chalky limestone sample was collected from the quarry of Nesher Israel Cement Enterprises Ltd. in Ramla (designated as 'chalky limestone'). Geological calcite crystals (Iceland Spar) were from Mexico and were purchased from Ward's (catalog no. 49H1600). Sea urchins were supplied by the Israel Oceanographic and Limnological Research Company, Eilat, Israel. All fresh plasters were made by calcination and slaking of the chalky limestone sample. Heating temperatures and times are listed in Table 1. Modern plasters A, C and D were slaked by placing ca. 30 grams of the calcined sample in a $400 \mathrm{ml}$ beaker, and adding an excess amount of water one day after the heating. A layer of 1-3 cm of plaster was formed in each beaker. Modern plaster B was slaked by the addition of excess water while the calcined rock was still hot in a cooking pot. A plaster layer 1-3 mm thick was formed. All plasters were left on the laboratory shelf for recarbonation at room temperature of $20-25^{\circ} \mathrm{C}$, without monitoring the environmental conditions. The recarbonating samples were monitored by infrared analysis, detecting the calcite formation and the decrease in the calcium hydroxide peak intensity (narrow, clear peak at $3643 \mathrm{~cm}^{-1}$ ). The Yiftahel plaster was collected from one of the floors of the pre-pottery Neolithic B strata on the site of Yiftahel (8 km north-west of Nazareth, lower Galilee, see Khalaily et al., 2008. The sample was taken from Building 501, square G17, L5098, and registered as B50183). The preparation modes of the modern ashes are listed in Table 1 . Ash $900^{\circ} \mathrm{C}$ was left after heating in a box on the shelf for air slaking and recarbonation. Sample depth did not increase $3 \mathrm{~mm}$. The archaeological ash was collected from an Iron Age layer at the site of Tell es-Safi/Gath (Area A, L111222).

2.2. Fourier transform infrared spectrometry (FTIR): A few milligrams of sample were homogenized and powdered in an agate mortar and pestle. About $0.3 \mathrm{mg}$ were left in the mortar and mixed with about $40 \mathrm{mg}$ of $\mathrm{KBr}$ and pressed into a $7 \mathrm{~mm}$ pellet using a manual hydraulic press (Specac). Each sample was measured repeatedly, either by repetitive grinding of the same $\mathrm{KBr}$ pellet or by using different aliquots of the same sample that were ground to different extents. Both methods produced the same results. All repetitive grindings were made by hand with an agate mortar and pestle. Typically, a 
few seconds of regrinding were applied. Infrared spectra were obtained at $4 \mathrm{~cm}^{-1}$ resolution for 32 scans using a Nicolet 380 instrument (Thermo). The baselines for the heights measurements of the $v_{3}, v_{2}$ and $v_{4}$ peaks were determined following the method of Chu et al. (2008). The $v_{2}$ and $v_{4}$ heights were normalized to a $v_{3}$ height of 1000 , corresponding to 1.0 Absorbance Unit.

2.3. Radiocarbon dating of geogenic calcites: 20-30 grams of each sample were crushed and dissolved in $5 \mathrm{~N} \mathrm{HCl}$ for $\mathrm{CO}_{2}$ extraction. The gas was chemically transformed (through $\mathrm{C}_{2} \mathrm{H}_{2}$ and $\mathrm{Li}_{2} \mathrm{C}_{2}$ ) into benzene for dating using a liquid scintillation counter at the Radiocarbon and Cosmogenic Isotopes Laboratory, Kimmel Center of Archaeological Science, Weizmann Institute of Science, Rehovot, Israel.

\section{Results}

FTIR analysis requires powdered samples, and it has been shown that differences in the amount of grinding affects peak widths and relative heights in different archaeological materials, including apatites and calcites (Chu et al., 2008; Surovell and Stiner, 2001). However, we find that by normalizing the $v_{2}$ and $v_{4}$ peak heights relative to the height of the $v_{3}$ peak, a consistent trend emerges that decouples the effect of grinding from the intrinsic order in the material. Calcite infrared spectra of an Iceland Spar crystal ground to different extents is shown in Figure 1a. It can be seen that the lightly ground sample (spectrum I) has wider peaks and a smaller $v_{2} / v_{4}$ height ratio than the heavily ground one (spectrum II). The widths of the peaks are measured by their full widths at half maximum (FWHM) values (see Fig.1a for illustration). The four calcite samples in Figure $1 \mathrm{~b}$ have distinctly different trend lines for the normalized $v_{2}$ versus $v_{4}$ peak heights. With increased grinding, the relative $v_{2}$ and $v_{4}$ peak heights decrease, and all peaks in the spectra narrow. As an example, the $v_{3}$ peak widths (FWHM) are included for the Iceland Spar calcite in Figure 1b. Since trend lines are produced, no special attention to the exact degree of repetitive grinding is required.

The different trend lines in Figure $1 \mathrm{~b}$ show that there is a systematic difference in the $v_{2}$ versus $v_{4}$ peak heights for calcites that were formed in different ways. The 
shallowest slope corresponds to a geogenic single crystal of Iceland Spar, which is known to have high atomic order over macroscopic length scales (Bragg, 1914; Gorton, 1916), while the steepest slope corresponds to a modern lime plaster. Modern ash and geogenic limestone fall in between, with the limestone being more similar to the geogenic Iceland Spar sample.

\subsection{Biogenic calcite}

In order to gain more insight into the significance of the changes in Figure 1, we analysed primary and secondary sea urchin spines, as well as a sea urchin test (body skeleton). Although the slopes of the three sea urchin skeletal element trend lines are fairly similar, significant separation between the trend lines is evident (Fig. 2). The trend line for the secondary spine is closer to that of the single sparry calcite crystal as compared to the primary spines. An earlier study indeed found textural differences between spines at different maturation levels, using X-ray diffraction (Aizenberg et al., 1997). We note that the location of the peak maximum of the $v_{4}$ peak shifts from $713 \mathrm{~cm}^{-1}$ to around $717 \mathrm{~cm}^{-1}$ for the sea urchin test, which reflects increasing magnesium incorporation into the calcite structure (Bischoff et al., 1985; Falini et al., 1998; Farmer, 1974).

\subsection{Calcitic ash}

The formation of ash calcite is unique. At around $500^{\circ} \mathrm{C}$, calcium oxalate $\left(\mathrm{CaC}_{2} \mathrm{O}_{4}\right)$ in the wood and bark degrades, loses carbon monoxide $(\mathrm{CO})$ and becomes calcite $\left(\mathrm{CaCO}_{3}\right)$ (Dollimore, 1987; Huaqing, 1989). If the ash temperature exceeds ca. $750^{\circ} \mathrm{C}$, the calcite will decompose to $\mathrm{CaO}$ and $\mathrm{CO}_{2}$, followed by water absorption and recarbonation back to form calcite (Boynton, 1980). Figure 3 is a plot of a variety of different modern ash calcites produced in the oven at $500^{\circ} \mathrm{C}$ or in bonfires. Although a small amount of the bonfires 'low temperature' ash decomposed to $\mathrm{CaO}$, as in 'high temperature' ash (based on the presence of the $\mathrm{Ca}(\mathrm{OH})_{2}$ infrared absorption peak at 3643

$\mathrm{cm}^{-1}$ ), the majority of the calcite was formed without this additional step. One ash sample 
(Modern Ash A) was reheated at $900^{\circ} \mathrm{C}$ to test differences at 'high temperature' ash. All the samples cluster around the same trend line, except for the one that was reheated to $900^{\circ} \mathrm{C}$, which has a much higher slope and is the furthest away from the sparry calcite trend line. We also note that one of the ash samples is from an archaeological site and is around 3000 years old. It falls within the cluster of the modern ash samples.

\subsection{Calcitic plaster}

Figure 4 shows a plot of the $v_{2}$ versus $v_{4}$ heights of four different modern plaster samples produced in the laboratory, as well as a detailed analysis of calcite samples from a piece of plaster from the PPNB site of Yiftahel (northern Israel) that is about 9,000 years old (Fig. 5). The modern plaster samples all fall on a well defined trend line, even though plasters $\mathrm{C}$ and $\mathrm{D}$ are not fully carbonated and still contain some calcium hydroxide (based on the infrared absorption peak at $3643 \mathrm{~cm}^{-1}$ ). The archaeological plaster samples are all below this line, but above the trend line for limestone. Limestone is the starting material for producing plaster. In the Yiftahel sample, limestone was also mixed into the sample to increase the bulk and improve its mechanical properties. The Yiftahel plaster samples extracted from the thin surface layer all fall on the same trend line. A sample from the rectangular inclusion (Fig. 5) also falls on this trend line. This may indicate that the rectangular piece was from an older plaster floor surface that was reconstructed and used as aggregates in the sampled floor. Analysis of the yellow basal layer itself (Fig.4 small dashes) yields a different trend line, closer to the limestone trend line. The locations of the trend lines observed in Figure 5 probably reflect the extent of mixing between the pyrogenic calcite, prepared by heating the raw material (such as limestone), and geogenic calcitic aggregates that were added to it.

\subsection{Geogenic calcite}

Figure 6 shows $v_{2}$ versus $v_{4}$ peak height plots of limestones and chalks obtained from various locations in Israel. One of the limestones (Fig. 6, 'Limestone B', from Tel Tsafit), a relatively well consolidated chalky limestone (from Ramle, Israel) and a chalk derived 
from a depth of 3 meters below the surface at Ramat Rahel (Fig. 6, 'Chalk A, -3m'), have trend lines close to that of the sparry single calcite crystal. Limestone A and especially the other two chalk samples derived from close to the extant ground surface are clearly less like the geogenic Iceland Spar than the first three mentioned samples. Radiocarbon and stable carbon isotopes measurements of the samples (Table 2) show that there was carbon exchange between the rock and the atmosphere in the not so distant past, which could lead to a diagenetic imprint on the formation of those chalk and limestone calcites.

\section{Discussion}

\subsection{Comparison of the trend line approach}

Here we present a new approach for differentiating between calcite crystals formed by different mechanisms, based on changes in the relative heights of their IR absorption peaks. This trend line method offers significant advantages over using a single $v_{2} / v_{4}$ height ratio, as we had used in an earlier study, to differentiate between geogenic calcite, ash calcite and plaster calcite (Chu et al., 2008). In order to normalize the effects grinding has on peak heights and widths, Chu et al. (2008) recommended that each sample be ground until the width of the $v_{3}$ peak falls in a "window" between 110 and $130 \mathrm{~cm}^{-1}$. In contrast, the new trend line method utilizes samples over a wide range of grinding, making the trend line independent of the degree to which any one sample is ground. By analyzing the same sample many times, the changes in the infrared spectrum due to grinding can be differentiated from the changes due to differences in the intrinsic order among calcites formed by different mechanisms. In this way, calcites formed by different mechanisms, as well as changes in a material due to diagenesis, or mixtures of calcites from different origins, can all be recognized more reliably.

We show that calcites formed by different mechanisms have characteristic trend lines when the normalized heights of the $v_{2}$ and $v_{4}$ peaks are plotted against each other. We observe a correlation between the extent of crystalline order and the slope and position of these different $v_{2}$ versus $v_{4}$ trend lines. A single crystal of sparry calcite has the lowest slope and is located to the extreme right of the $\mathrm{v}_{2}$ versus $\mathrm{v}_{4}$ peak height plot (Fig. 7). These calcite crystals are known to have extremely high atomic order over 
macroscopic length scales (Bragg, 1914; Gorton, 1916). In contrast, calcite from other origins does not exhibit this same extent of order. Although biogenic samples can also be highly crystalline at a local atomic level, a detailed synchrotron X-ray diffraction study showed that primary sea urchin spines have perfectly ordered domains that are larger than those of the secondary spines, but smaller than those of sparry calcite (Aizenberg et al., 1997). On the other hand, the same study showed that the extent of anisotropy of the secondary spines is higher than the primary spines, and similar to the anisotropy of pure synthetic calcite. We note that trend lines of the primary and secondary spines are separated in Figure 2, and that the trend line of the secondary spines is closer to the trend line of sparry calcite. Biological calcites can also contain magnesium, and this has an affect on the $v_{4}$ peak (Bischoff et al., 1985; Falini et al., 1998; Farmer, 1974). The test contains the most magnesium from the three analyzed samples, while the secondary spines have the lowest amount (Zolotoyabko et al., 2010), and this may also affect the trend lines.

The correlation between trend line slope and position with differences in the intrinsic order suggests that our IR-based analysis method could provide insights for future studies into the processes involved in pyrogenic calcite formation.

\subsection{Possible archaeological applications}

As calcite is a common component of sediments in many archaeological sites, this mode of analysis can be used to identify the source of the calcite, namely geogenic, biogenic, and pyrogenic in the form of ash or in the form of plaster. This differentiation is only possible if the calcite is relatively well preserved, as recrystallization of the calcite will most likely change the atomic order. In fact, the scattering in the data points and/or an absence of a well defined trend line may well indicate that the calcite has been altered diagenetically. One way to independently assess the preservation state of the calcite is to determine whether gastropod shells or the shells of fresh water bivalves that are in the proximity of the calcite sample under investigation are still composed of $100 \%$ aragonite. As aragonite is less stable than calcite at ambient temperatures, this is a good indication that the calcite should also be well preserved (Weiner, 2010). 
Ash calcite is often produced in large amounts in archaeological sites. The trend lines for low and high temperature ash are quite different (Fig. 3). The plot can thus be used to identify ash produced in high-temperature industries (above ca. $800^{\circ} \mathrm{C}$ ) such as metal production or in certain ceramic kilns. Note that even though the high temperature ash and the fresh plasters were calcined and slaked (although by a different slaking method), each has a different trend line (Fig. 7). This implies that characteristics of the initial calcite affect the trend line position and slope despite the calcination and recarbonation processes.

As ash calcite is fine-grained and can easily be dispersed by wind and/or trampling, it is often not easy to identify ash especially when mixed with other sedimentary minerals. The trend line of the common form of ash produced at $500^{\circ} \mathrm{C}$ is quite distinct from limestone and plaster, but does overlap with chalk. The presence of chalk at a site not only complicates the identification of ash, but because chalk itself undergoes diagenesis when close to the sediment surface, it may not have a consistent order. One interesting potential geochemical application is to use this method to identify well preserved chalk that still has the biogenic order of the original skeletal elements that make up the chalk. This "pristine" chalk may provide stable isotope and trace element values that can be reliably used for reconstructing past climates at the time the organisms that produced the skeletons lived in the ocean.

We demonstrate the usefulness of the method for two archaeological samples. Figure 3 shows that the trend line of a 3000 year old archaeological ash sample overlies the trend lines of modern ash samples. This implies that this archaeological ash is well preserved. Figure 4 shows the analysis of a 9000 year old plaster sample, compared with modern fresh plasters and limestone; the primary materials used for preparing this plaster. The thin layer on the surface of the plaster (Fig. 5) has a trend line close to the fresh plaster. Furthermore all the samples analyzed from the surface (within a 30x10 $\mathrm{cm}$ sample) all fall on the same trend line. This shows that the surface plaster is homogenous, and was probably produced from a thin layer of smooth hydrated lime $\left(\mathrm{Ca}(\mathrm{OH})_{2}\right)$. This trend line however does not overlap with the modern plaster line, indicating that some diagenetic changes have taken place on the plaster surface resulting in a shift of the trend line towards the sparry calcite trend line. The lower yellow layer in the plaster contains 
geogenic calcite aggregates (Fig. 5). These aggregates produce a trend line located lower in the plot, closer to the limestone trend line. Note that both diagenesis and mixing with geogenic limestone may result in a lower trend line for a plaster sample.

In our analysis of geogenic chalk deposits at Ramat Rahel (Fig. 6, 'Chalk A'), we observed that the data points of the chalk close to the present day surface are closer to those of fresh plaster compared with chalk from the same rock formation located 3 meters below the surface (Fig. 6). This is unexpected, as diagenesis of calcite usually involves dissolution followed by recrystallization, which should result in a calcite product that is similar to geogenic sparry calcite. This may indicate that in this chalk the diagenetic process involves some other mechanism of reorganization of the calcite crystals. We also observed that these geological chalks produced finite radiocarbon ages, implying that diagenesis is "ongoing". When such diagenetic chalk is incorporated into plaster or mortar as an aggregate, it might cause difficulties when dating the plaster/mortar by the sequential dissolution method (Lindroos et al., 2007). This method is based on differences in dissolution rates between the pyrogenic calcite of the binder and the geogenic calcite of the aggregates. Based on Figure 6, the diagenetic chalk might have a similar dissolution profile to the pyrogenic calcite, and thus affect the interpretation of the radiocarbon results. Therefore, analyzing the infrared spectrum of the plaster/mortar aggregates by the method proposed here might predict possible difficulties that may arise during the sequential dissolution procedure.

It is often very useful to be able to identify the type of calcite encountered during an excavation using an infrared spectrometer on site. As it is cumbersome to run multiple infrared spectra for each sample, we recommend preparing a "master plot" of the main primary materials at the site that includes the common geogenic calcites, as well as the trend lines for modern ash and plaster. Such a plot is shown in Figure 7. The individual analyses can then be located on the master plot and preliminary conclusions can be drawn about their origins of formation. For more detailed analysis, we would recommend analyzing the same sample after homogenization several times with different extents of grinding, rather than regrinding the same $\mathrm{KBr}$ pellet, for a better representation of the original sample material. 


\section{Conclusions}

The normalized $v_{2}$ versus the $v_{4}$ peaks height trend lines for samples ground to different extents is an efficient, rapid, and effective tool to distinguish between well preserved calcites formed by different processes. The basis for this differentiation correlates with characteristic differences of local and extended atomic order in the calcite. This analysis method can be applied with an on-site infrared spectrometer during an excavation, and enables the identification of different calcite types, as well as a means of assessing their preservation states.

\section{Acknowledgements}

We would like to thank Eugenia Mintz for help with the radiocarbon dating, and to all the people who provided us with samples or allowed us to collect samples from the sites under their supervision: Dr Yael Politi for the sea urchin samples; Dr Dan Shavit from Nesher Cement Enterprises Ltd.; Ido Rasis, Keren Kayemeth LeIsrael for supplying the wood for the open bonfires; Shira Gur-Arie for supplying us with Modern Ash B and the archaeological ash samples; Prof Richard Freund and Prof Rami Arav for the ancient wood from the Cave of Letters; Drs Hamoudi Khalaily, Ianir Milevski and Nimrod Getzov from the Yiftahel excavations; Prof Aren Maeir from the Tell es-Safi/Gath Archaeological Project; Prof Oded Lipschits and Dr Yuval Gadot from Ramat-Rachel excavations; Drs Ilan Sharon and Ayelet Gilboa from Tel Dor excavation; and Mr Ulf Fornhammar for introducing us to calcite calcination using open bonfires. The research leading to these results has received funding from the European Research Council under the European Community's Seventh Framework Programme (FP7/2007-2013) / ERC grant agreement $\mathrm{n}^{\circ} 229418$.

\section{References:}

Addadi, L., Raz, S. and Weiner, S., 2003. Taking advantage of disorder: amorphous calcium carbonate and its roles in biomineralization. Advanced Materials 15, 959-970. 
Aizenberg, J., Hanson, J., Koetzle, T. F., Weiner, S. and Addadi, L., 1997. Control of macromolecule distribution within synthetic and biogenic single calcite crystals. Journal of the American Chemical Society 119 (5), 881-886.

Beniash, E., Aizenberg, J., Addadi, L. and Weiner, S., 1997. Amorphous calcium carbonate transforms into calcite during sea urchin larval spicule growth. Proceedings of the Royal Society of London Series B-Biological Sciences 264 (1380), 461-465.

Bischoff, W. D., Sharma, S. K. and Mackenzie, F. T., 1985. Carbonate Ion Disorder in Synthetic and Biogenic Magnesian Calcites - a Raman Spectral Study. American Mineralogist 70 (5-6), 581-589.

Borrelli, E., 1999. Binders - ARC Laboratory Handbook, ICCROM ARC Laboratory Handbbok, ICCROM, Rome.

Boynton, R. S., 1980. Chemistry and Technology of Lime and Limestone, John Wiley \& Sons, New York.

Bragg, W. L., 1914. The analysis of crystals by the X-ray spectrometer. Proceedings of the Royal Society of London 89 (613), 468-489.

Canti, M. G., 2003. Aspects of the chemical and microscopic characteristics of plant ashes found in archaeological soils. Catena 54 (3), 339-361.

Chu, V., Regev, L., Weiner, S. and Boaretto, E., 2008. Differentiating between anthropogenic calcite in plaster, ash and natural calcite using infrared spectroscopy: implications in archaeology. Journal of Archaeological Science 35, 905-911.

Dollimore, D., 1987. The thermal decomposition of oxalates. A review. Thermochimica Acta 117, 331-363.

Duyckaerts, G., 1959. The infra-red analysis of solid substances. Analyst 84, 201-214.

Falini, G., Fermani, S., Gazzano, M. and Ripamonti, A., 1998. Structure and morphology of synthetic magnesium calcite. Journal of Materials Chemistry 8 (4), 1061-1065.

Farmer, V. C., 1974. The Infrared Spectra of Minerals, Mineralogical Society, London. 
Gago-Duport, L., Briones, M. J. I., Rodríguez, J. B. and Covelo, B., 2008. Amorphous calcium carbonate biomineralization in the earthworm's calciferous gland: pathways to the formation of crystalline phases. Journal of Structural Biology 162, 422-435.

Gorton, W. S., 1916. The X-ray spectrum of Tungsten. Physical Review VII (2), 203208.

Gueta, R., Natan, A., Addadi, L., Weiner, S., Refson, K. and Kronik, L., 2007. Local atomic order and infrared spectra of biogenic calcite. Angewandte Chemie International Edition 46, 291-294.

Huaqing, L., 1989. Effect of chemical adsorption of calcium oxalate monohydrate on DTA baseline. Thermochimica Acta 141, 151-157.

Khalaily, H., Milevski, I., Getzov, N., Hershkovitz, I., Barzilai, O., Yarosevich, A., Shlomi, V., Najjar, A., Zidan, O., Smithline, H. and Liran, R., 2008. Recent Excavations at the Neolithic Site of Yiftahel (Khalet Khalladyiah), Lower Galilee. Neo-Lithics 2/08, $3-11$.

Lane, M. D., 1999. Midinfrared optical constants of calcite and their relationship to particle size effects in thermal emission spectra of granular calcite. Journal of Geophysical Research-Planets 104 (E6), 14099-14108.

Lindroos, A., Heinemeier, J., Ringbom, A., Brasken, M. and Sveinbjornsdottir, A., 2007. Mortar dating using AMS C-14 and sequential dissolution: Examples from medieval, non-hydraulic lime mortars from the Aland Islands, SW Finland. Radiocarbon 49 (1), 4767.

Lipschits, O., Oeming, M., Gadot, Y. and Arubas, B., 2009. The 2006 and 2007 Excavation Seasons in Ramat Rahel. Israel Exploration Journal 59, 1-20.

Maeir, A. (ed.), in press. Tell es-Safi/Gath I: Report on the 1996-2005 Seasons. Ägypten und Altes Testament 69. Wiesbaden: Harrassowitz.

Pettijohn, F., 1957. Sedimentary Rocks, 2nd, Harper \& Row, New York. 
Politi, Y., Arad, T., Klein, E., Weiner, S. and Addadi, L., 2004. Sea urchin spine calcite forms via a transient amorphous calcium carbonate phase. Science 306 (5699), 11611164.

Politi, Y., Metzler, R. A., Abrecht, M., Gilbert, B., Wilt, F. H., Sagi, I., Addadi, L., Weiner, S. and Gilbert, P. U. P. A., 2008. Transformation mechanism of amorphous calcium carbonate into calcite in the sea urchin larval spicule. . Proceedings of the National Academy of Science (USA), 17362-17366.

Ruppin, R. and Englman, R., 1970. Optical Phonons of Small Crystals. Reports on Progress in Physics 33 (2), 149-196.

Sharon, I., Gilboa, A. and Shalev, Y., 2009. Tel Dor 2005: Preliminary Report. Hadashot Arkheologiyot - Excavations and Surveys in Israel 121.

Surovell, T. A. and Stiner, M. C., 2001. Standardizing infrared measures of bone mineral crystallinity: an experimental approach. Journal of Archaeological Science 28, 633-642. Weiner, S., 2010. Microarchaeology. Beyond The Visual Archaeological Record, Cambridge University Press.

Zolotoyabko, E., Caspi, E. N., Fieramosca, J. S., Von Dreele, R. B., Marin, F., Mor, G., Politi, Y., Addadi, L. and Weiner, S., 2010. The differences between bond lengths in biogenic and geological calcite. Crystal Growth and Design 10 (3), 1207-1214. 
Table 1. Preparation modes of modern plaster and ash samples.

\begin{tabular}{|c|c|c|c|c|c|c|}
\hline Sample & Lab Number & Raw Material & Heating Device & Temperature & Duration & Date \\
\hline $\begin{array}{c}\text { Modern } \\
\text { Plaster A }\end{array}$ & DS2III1 & Chalky limestone & Open bonfire & $965^{\circ} \mathrm{C}$ (average) & $3 \mathrm{hrs}$ & 1.2 .07 \\
\hline $\begin{array}{c}\text { Modern } \\
\text { Plaster B }\end{array}$ & DS1III2pot & Chalky limestone & Open bonfire & $980^{\circ} \mathrm{C}$ (average) & $3 \mathrm{hrs}$ & 1.2 .07 \\
\hline $\begin{array}{c}\text { Modern } \\
\text { Plaster C }\end{array}$ & $\begin{array}{c}\text { Nesher } \\
29.1 .08\end{array}$ & Chalky limestone & Lab oven & $900^{\circ} \mathrm{C}$ & $1 \mathrm{hr}$ & 29.1 .08 \\
\hline $\begin{array}{c}\text { Modern } \\
\text { Plaster D }\end{array}$ & DS1III3 & Chalky limestone & Open bonfire & $980^{\circ} \mathrm{C}$ (average) & $3 \mathrm{hrs}$ & 1.2 .07 \\
\hline Modern Ash A & R2 bag 1 & Various wood types & Open bonfire & $805^{\circ} \mathrm{C}$ (average) & $8 \mathrm{hrs}$ & 31.1 .07 \\
\hline Modern Ash B & SGA10 & Various wood types & Open bonfire & $620^{\circ} \mathrm{C}$ (average) & $3 \mathrm{hrs}$ & 21.7 .07 \\
\hline $\begin{array}{c}\text { Modern Ash C } \\
\text { Pine, rings } \\
5,17-19\end{array}$ & Pine bark & Lab oven & $500^{\circ} \mathrm{C}$ & $2 \mathrm{hrs}$ & 26.7 .09 \\
\hline $\begin{array}{c}\text { Modern Ash } \\
\text { from Ancient } \\
\text { Wood }\end{array}$ & $\begin{array}{c}\text { RT5911 } \\
\text { from the Cave of } \\
\text { Ash } 900^{\circ} \mathrm{C}\end{array}$ & $\begin{array}{c}\text { R2 bag 1, } \\
900\end{array}$ & Lab oven & $500^{\circ} \mathrm{C}$ & $1 \mathrm{hr}$ & 8.12 .09 \\
\hline
\end{tabular}


Table 2. ${ }^{14} \mathrm{C}$ and $\delta{ }^{13} \mathrm{C}$ values of various geogenic calcites.

\begin{tabular}{|c|c|c|}
\hline Sample & pmc & $\delta^{13} \mathrm{C}$ \\
\hline Chalk A (-1m) & $12.06 \pm 0.11$ & $-7.4 \% 0$ \\
\hline Chalk B & $2.08 \pm 0.23$ & $-1.4 \% 0$ \\
\hline Limestone A & $2.38 \pm 0.07$ & $-4.1 \% 0$ \\
\hline Chalk A (-3m) & $1.17 \pm 0.05$ & $-6.3 \% 0$ \\
\hline Chalky limestone & $0.90 \pm 0.10$ & $+1.8 \%$ \\
\hline Background (marble) & $0.65 \pm 0.06$ & $+2.4 \%$ \\
\hline
\end{tabular}




\section{Figure captions:}

Fig. 1. (a) Infrared spectra of calcite, ground to different extents. The sample measured is an Iceland Spar crystal. I - Lightly ground sample. The designation of the peaks as $v_{3}, v_{2}$ and $v_{4}$ is marked, and baselines are shown for the measurements of the $v_{2}$ and $v_{4}$ heights. II - Heavily ground sample. The baseline used for the height measurement of the $v_{3}$ peak is shown. The length (in wavenumbers) of the horizontal line at the half height of the $v_{3}$ peak is the full width at half maximal height value (FWHM). The FWHM values of the

presented peaks are: Spectrum I $-v_{3}=127 \mathrm{~cm}^{-1}, v_{2}=14 \mathrm{~cm}^{-1}, v_{4}=7.4 \mathrm{~cm}^{-1}$. Spectrum II $-v_{3}=89 \mathrm{~cm}^{-1}, v_{2}=10.6 \mathrm{~cm}^{-1}, v_{4}=7.0 \mathrm{~cm}^{-1}$. The $v 2 / v 4$ heights ratios are: Spectrum I2.1. Spectrum II - 3.8. (b) Plot of the $v_{2}$ versus $v_{4}$ peak heights of geogenic and pyrogenic calcites after each spectrum was normalized to the corresponding $v_{3}$ peak height. For each type of calcite, data points correspond to successive grindings of the same specimen. The values along the trend line for the sparry calcite crystal sample designate the width (FWHM) of the $v_{3}$ peak. (n.a.u. - normalized absorbance units).

Fig. 2. Plot of the $v_{2}$ versus $v_{4}$ peak heights of various biogenic calcites. The black line corresponds to the sparry calcite crystal polynomial trend line from Figure 1. (n.a.u. - normalized absorbance units).

Fig. 3. $v_{2}$ and $v_{4}$ peak heights of various ash calcites. The black line corresponds to the sparry calcite polynomial trend line from Figure 1. Modern ashes A,B,C were produced from modern woods (see Table 1 for details on all modern ashes). Modern ash from ancient wood was made by burning a 2000 year old wood from the Cave of Letters (Dead Sea area, Israel). The archaeological ash is a 3000 year old ash sample from Tell esSafi/Gath. (n.a.u. - normalized absorbance units).

Fig. 4. $v_{2}$ and $v_{4}$ peak heights of various plaster calcites. The black line shows the sparry calcite single crystal polynomial trend line from Figure 1. The modern plaster preparation modes appear in Table 1. The archaeological samples fall in the grey area, between the geogenic raw materials and the fresh plasters. (n.a.u. - normalized absorbance units). 
Fig. 5. A section of a PPNB plaster floor from the site of Yiftahel. Three layers can be seen: A top thin surface layer (A), a second red shaded layer (B), and a lower basal yellow colored layer $(\mathrm{C})$. An asterisk marks a white rectangular piece, similar in color and texture to the surface layer.

Fig. 6. $v_{2}$ and $v_{4}$ peak heights of various geogenic calcites. The black line corresponds to the sparry calcite single crystal polynomial trend line from Figure 1 . The $-1 \mathrm{~m}$ and $-3 \mathrm{~m}$ in the Chalk A refer to samples derived from 1 meter and 3 meters below ground surface level. (n.a.u. - normalized absorbance units).

Fig. 7. Plot of the $v_{2}$ versus $v_{4}$ peak height trend lines of geogenic and pyrogenic calcites. Note that only the linear portions are shown. The trend lines are based on data presented in Figs. 1 and 3. (n.a.u. - normalized absorbance units). 
Figure 1

a

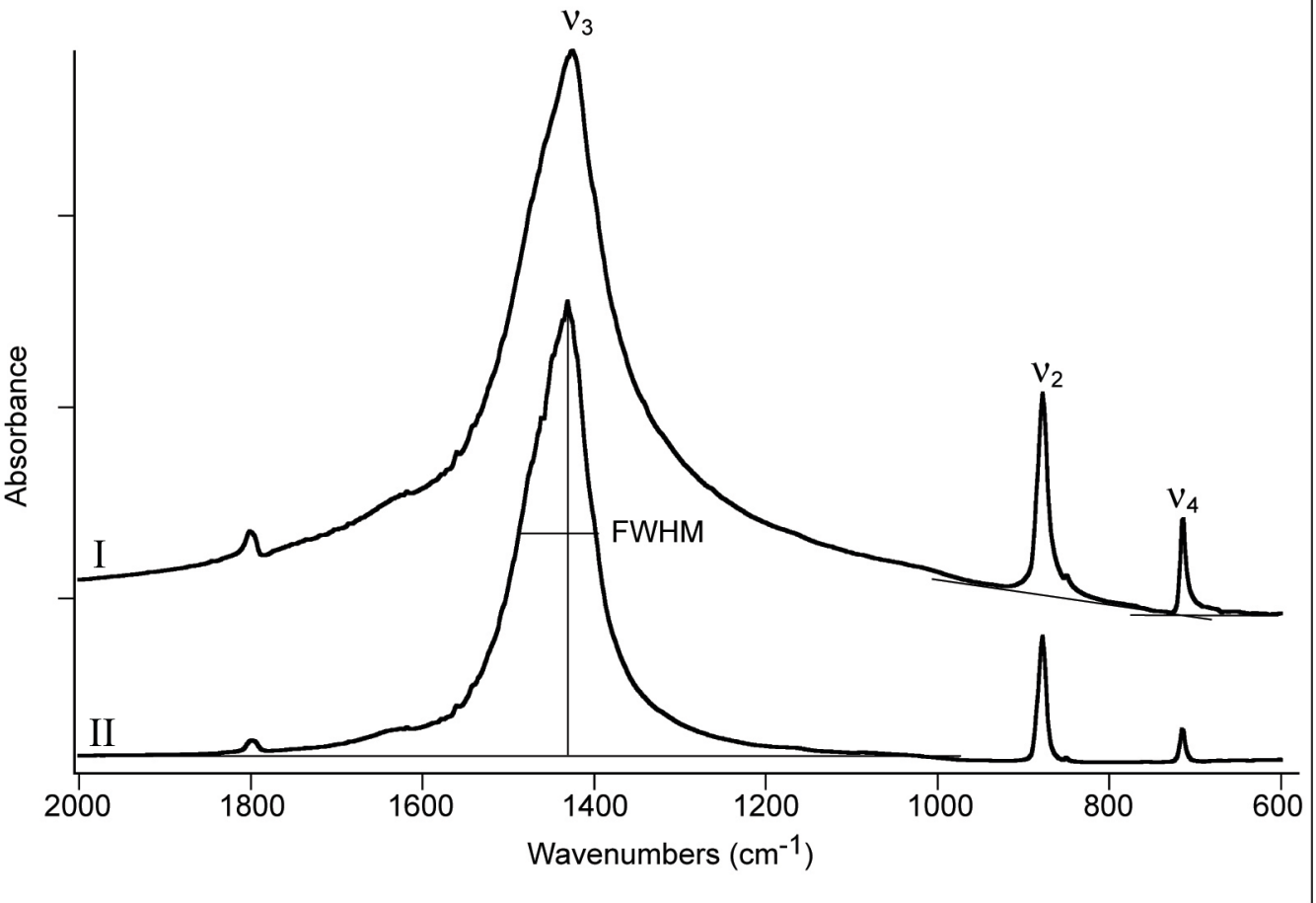

b

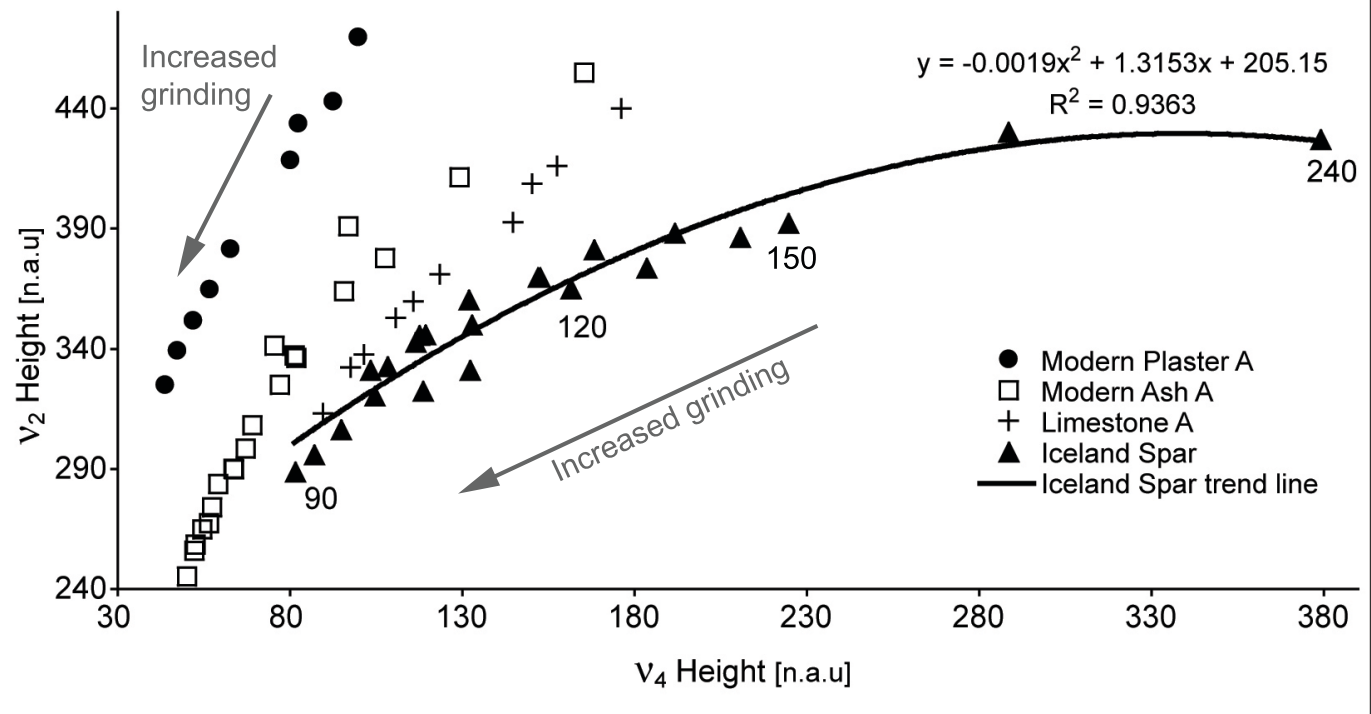




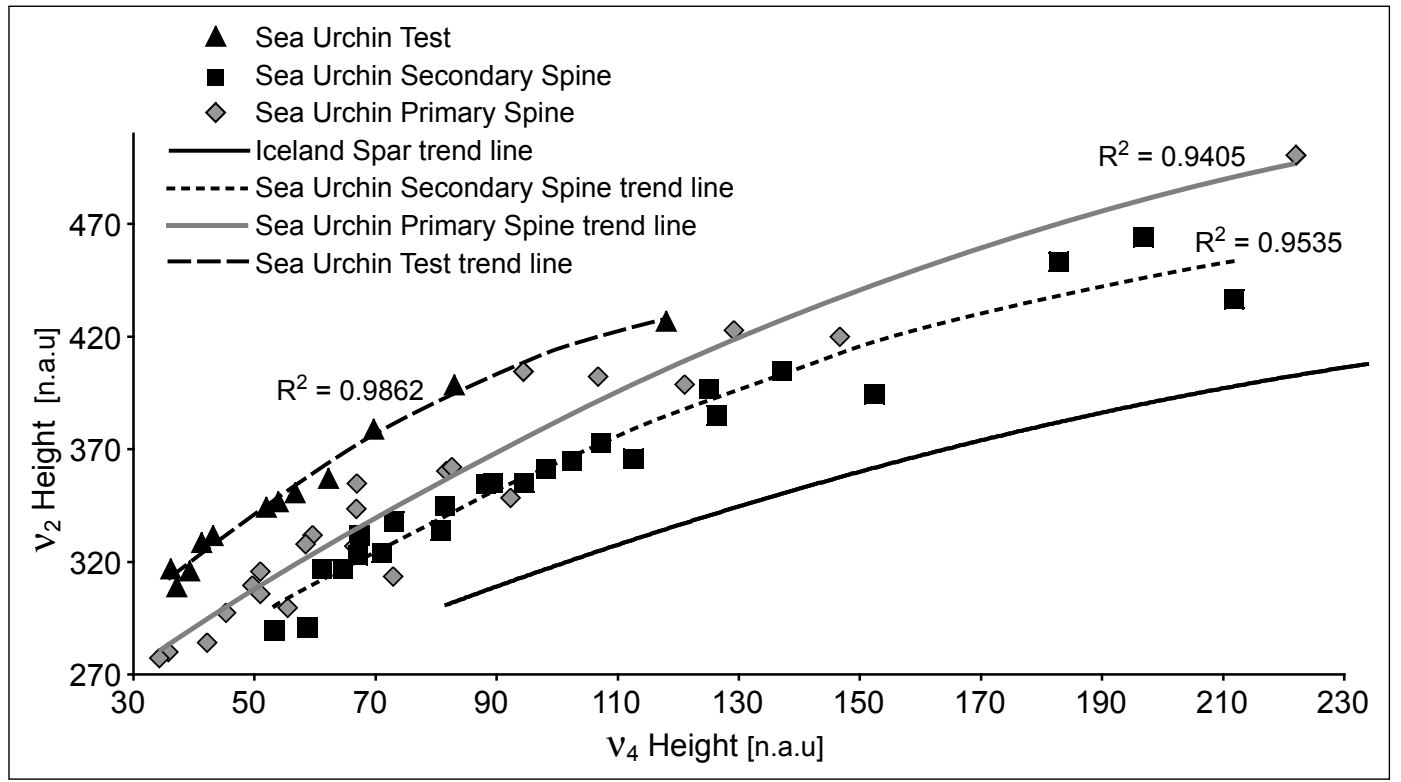




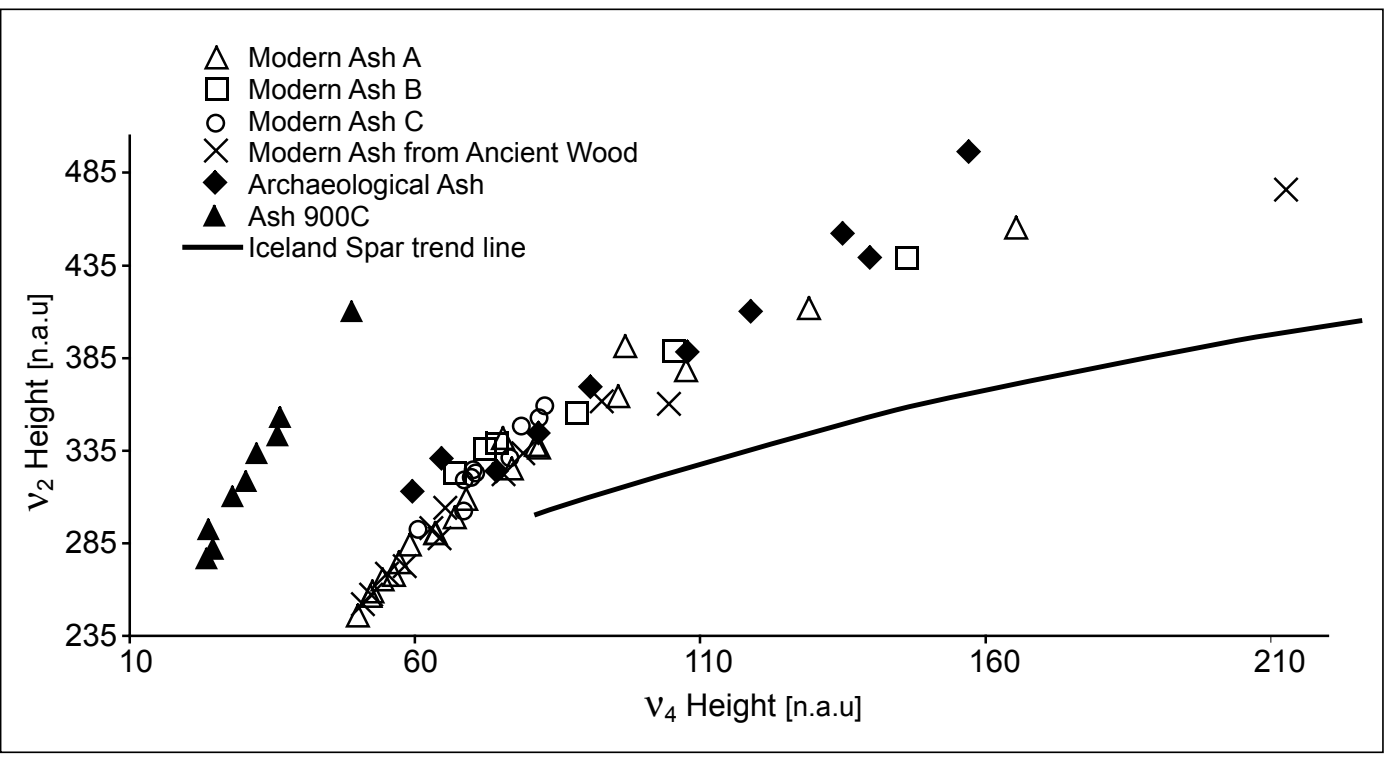




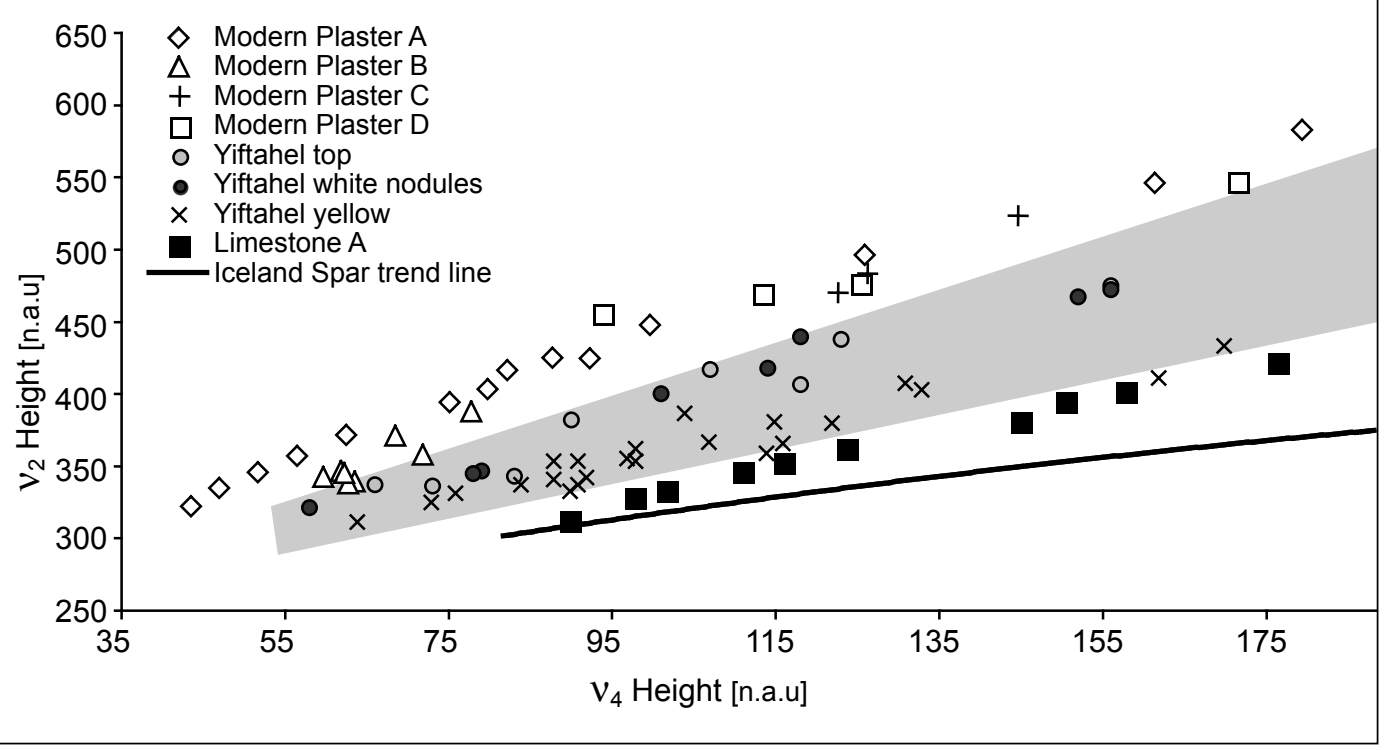




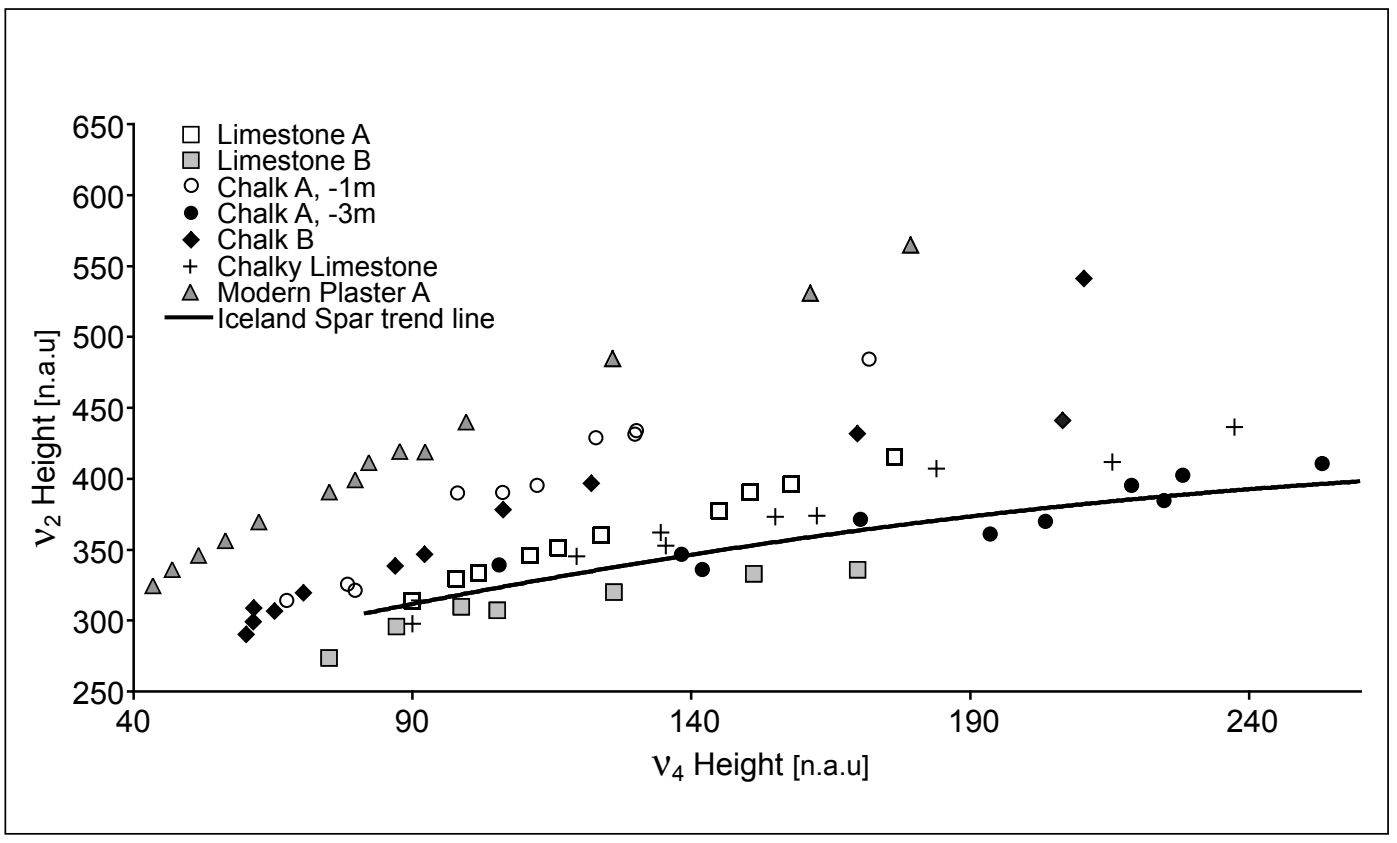




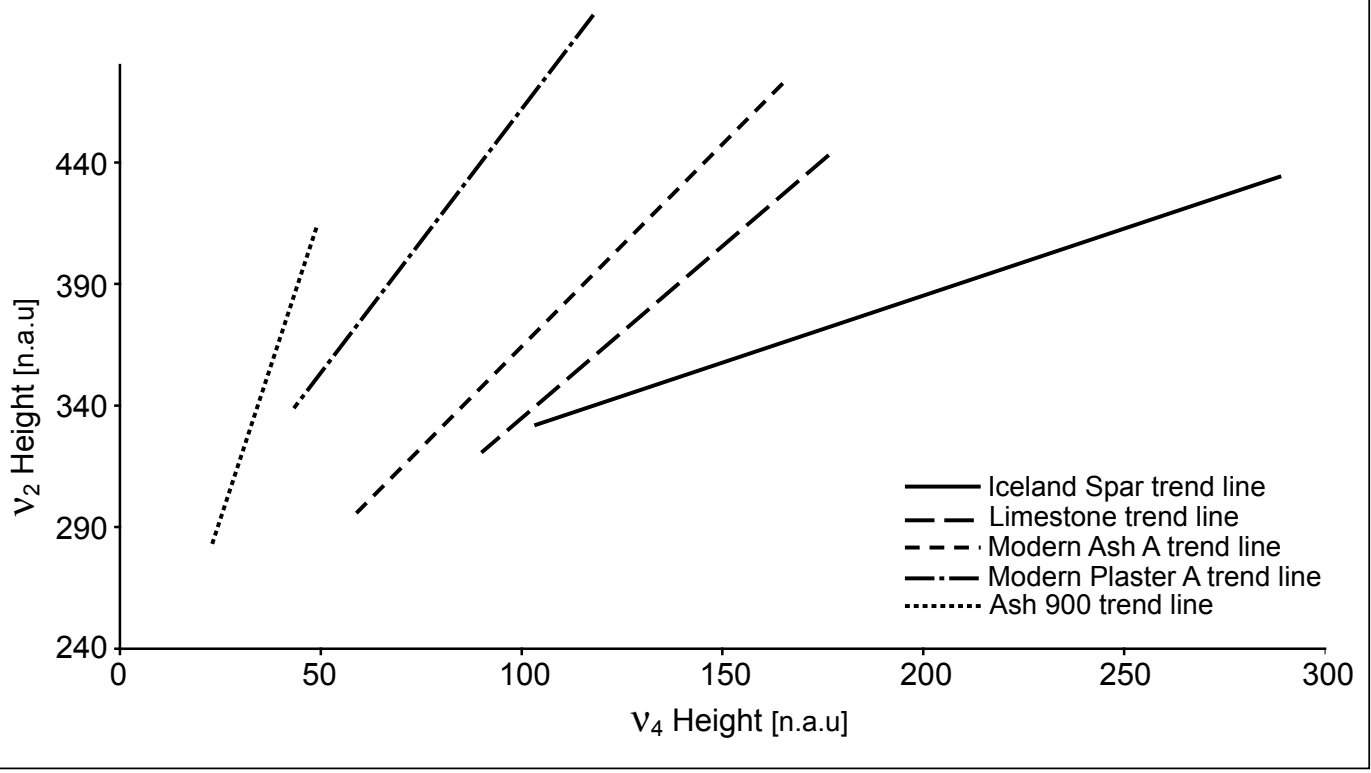

